\title{
A COMPARATIVE STUDY OF URANS, DDES AND DES SIMULATIONS OF JETSTREAM 31 AIRCRAFT NEAR THE COMPRESSIBILITY LIMIT
}

\author{
HRISHABH CHAUDHARY \\ Centre for Computational Engineering Sciences, Cranfield University, \\ Cranfield, Bedfordshire, MK43 0AL, United Kingdom \\ hrishabh.chaudhary@cranfield.ac.uk \\ NiCOLAS LEDOS \\ Centre for Computational Engineering Sciences, Cranfield University, \\ Cranfield, Bedfordshire, MK43 0AL, United Kingdom \\ nicolas.ledos@cranfield.ac.uk \\ LÁSZLÓ KÖNÖZSY \\ Centre for Computational Engineering Sciences, Cranfield University, \\ Cranfield, Bedfordshire, MK43 0AL, United Kingdom \\ laszlo.konozsy@cranfield.ac.uk
}

[Received: October 21, 2021; Accepted: November 19, 2021]

Dedicated to Professor Tibor Czibere on the occasion of his 90th birthday

\begin{abstract}
This work presents a comparative study of Unsteady Reynolds-Averaged NavierStokes (URANS), Detached Eddy Simulations (DES) and Delayed Detached Eddy Simulations (DDES) turbulence modeling approaches by performing numerical investigation with the ANSYS-FLUENT software package on a full-scale model of the Jetstream 31 aircraft. The lift and drag coefficients obtained from different models are compared with flight test data, wind tunnel data and theoretical estimates. The different turbulence models are also compared with each other on the basis of pressure coefficient distributions and velocity fluctuations along various lines and sections of the aircraft. For the mesh and the conditions presented in this study, the DDES Spalart-Allmaras model gives the best overall results.
\end{abstract}

Mathematical Subject Classification: 76G25, 76M12, 76F60, 76F55

Keywords: Jetstream 31, URANS, DES, DDES, Transient Computational Fluid Dynamics

\section{INTRODUCTION}

For advanced unsteady turbulence modeling, computational science and high performance computing have now become indispensable. Although Computational Fluid Dynamics (CFD) and Finite Element Analysis (FEA) cannot fully replace the experimental testing, it can undoubtedly expedite and complement the experimental results if done with the proper knowledge. Due to the advancements in the performance of the Graphics Processing Unit (GPU) and Central Processing Unit (CPU) performances, it is now possible to perform the transient simulations on a full-scale model of an aircraft using the turbulence technique of Detached Eddy Simulation (DES) and Delayed Detached Eddy Simulation (DDES) in a relatively short time. In 
this study, the results from Unsteady Reynolds-Averaged Navier Stokes (URANS), DES and DDES simulations over Jetstream 31 aircraft are compared with the flight test data and wind tunnel results.

Parker [1] developed a Computer-Aided Design (CAD) model of the Jetstream 31 aircraft by scanning a tenth scaled 3D model, which was used to perform experimental tests in the wind tunnel. In 2008, Leung 2 used this geometry to perform a CFD simulation around the aircraft baggage pod to perform a structural analysis and obtain aerodynamic loads. However, it was not until 2012 that the whole Jetstream 31 aircraft was simulated by Vessot [3] without taking into account the propeller effects. The relative difference was $15-20 \%$ between simulation results and flight test data provided by the National Flying Laboratory Centre (NFLC) at Cranfield University, but the study could not predict the maximum lift coefficient $\mathrm{C}_{\text {Lmax }}$ correctly. Simultaneously, Hodara [4] developed a User-Defined Function (UDF) for simulating the propeller of a half Dornier-228-101 aircraft model using an actuator disk based on the general momentum theory. Then, in 2013, Le Pajolec [5] took advantage of the previous studies to introduce the propeller effects into the full Jetstream 31 aircraft simulation. Le Pajolec [5] used the blade element momentum theory for the propellers and obtained less accurate results than the previous studies had. The results showed an improvement in the lift coefficient values but lower agreement in the drag coefficient. The following year, Jacques 6 and Lawson et al. [7] studied four configurations of the aircraft: without a propeller, with two engines, and without the left and right propeller. A hybrid mesh convergence was studied, and the lift coefficient $C_{L}$ and drag coefficient $C_{D}$ were predicted within a $5-16 \%$ of error with respect to the flight test data. In addition, the propeller-wing interference was analyzed by plotting spanwise and chordwise pressure distributions. In 2016, Fayyad 8 studied seven flight conditions including the propeller effects with the general momentum theory. The study analyzed drag, lift, slipstream velocity, velocity jump and propeller efficiency. Moreover, a preliminary study was carried out on Multiple Rotating Frames (MRF) and Sliding Mesh Models (SMM) with two types of meshes. In the same year, Zhu [9] used a feathered propeller designed in CATIA software and simulated in ANSYSFLUENT R19.1 to compare the results with the general momentum theory. Finally, in 2017, Casadei et al. [10 focused on the analysis of the Jetstream 31 without one engine. Different angles of attack and sideslip were studied using a steady-state RANS and transient DES Realizable $k-\epsilon$ model with an unstructured mesh with 6 million elements. A grid convergence study was performed and the relative difference was between 2-16\%. Furthermore, lift, drag and moment coefficients with different control surfaces were compared.

In most previous studies, the CFD of the full Jetstream 31 aircraft was based on steady-state RANS simulations and in one study simulations were performed with DES Realizable $k-\epsilon$. This study performs transient simulations of the Jetstream 31 aircraft using URANS, DES, and DDES modeling approaches on an unstructured grid and compares the performance of each technique with fight data, wind tunnel tests and theoretical estimates. 


\section{Methodology}

2.1. Governing equations. In the present work, the numerical investigations on the Jetstream 31 aircraft are performed using ANSYS-FLUENT R19.1. The governing equations as used in ANSYS-FLUENT R19.1 for unsteady, viscous and compressible flow are provided in equations 2.1 to 2.3 . In URANS simulations, the standard $k-\epsilon$ [11, Realizable $k-\epsilon$ 12], Renormalization Group (RNG) $k-\epsilon$ [13], and Shear Stress Transport (SST) $k-\omega[14$ models are used for the turbulence closure. Another turbulence modeling approach used in this study is Detached Eddy Simulation (DES), where the URANS approach is used in the boundary layer and Large-Eddy Simulation (LES) is used after massive separation within a single formulation. An essential requirement for DES is that the grid space should be of LES quality, otherwise, it will produce results mixing URANS and LES components. A problem arises while using DES for meshes with high aspect ratios in the boundary layer, as this generates grid-induced separation due to an activation of the DES limiter in the URANS region. To overcome this, Delayed DES (DDES) approach is used, which preserves the RANS model throughout the boundary layer. The main idea of DDES is to include the molecular and turbulent viscosity information into the switching mechanism to delay this switching in boundary layers. In the present work, the DES with SpalartAllmaras as proposed by Shur et al. 15] and DES with standard $k-\epsilon$ are also used for the turbulence closure. The mass, momentum and energy conservation equations can be written as follows:

$$
\begin{gathered}
\frac{\partial \rho}{\partial t}+\nabla \cdot(\rho \mathbf{u})=0 \\
\frac{\partial(\rho \mathbf{u})}{\partial t}+\nabla \cdot(\rho \mathbf{u} \otimes \mathbf{u})=\rho \mathbf{g}-\nabla p+\nabla \cdot \underline{\underline{\tau}}, \\
\frac{\partial E}{\partial t}+\nabla \cdot[(E+p) \mathbf{u}]=-\nabla \cdot \mathbf{q}+\nabla \cdot(\mathbf{u} \cdot \underline{\underline{\tau}}),
\end{gathered}
$$

where $t$ is the time, $\rho$ is density of the fluid, $\mathbf{u}$ is the velocity vector, $\mathbf{g}$ is the gravity vector, $p$ is the pressure field, $\underline{\underline{\tau}}$ is viscous stress tensor, $E$ is the total energy and $\vec{q}$ is the heat flux vector, respectively.

2.2. Geometry. The CAD model of the Jetstream 31 aircraft was developed by Parker 1], using a 3D non-contact scanning process. It is generated using a scanned version of the Cranfield Jetstream 31 tenth-scaled wind tunnel model. The geometrical differences between the actual aircraft and the model are highlighted in Table 1.

These minor differences in geometry will contribute to the differences in actual flight test data and the CFD results. Therefore, to have a more accurate comparison, the results from the wind tunnel and theoretical prediction of Cooke [16 will be considered. The theoretical predictions are performed using the airfoil section of the Jetstream 31 aircraft, which is similar to NACA 63A412. The drag polar and the lift curve slope results of flight test data, wind tunnel and theoretical predictions are provided in Table 2, where the angle of attack is in degrees. 
Table 1. Geometrical differences between actual aircraft and CAD model

\begin{tabular}{lll}
\hline Aircraft section & CAD model & Aircraft \\
\hline Aircraft length & $14.31 \mathrm{~m}$ & $14.36 \mathrm{~m}$ \\
Wing span & $15.83 \mathrm{~m}$ & $15.85 \mathrm{~m}$ \\
Wing tip chord & $0.830 \mathrm{~m}$ & $0.790 \mathrm{~m}$ \\
Wing surface & $25.60 \mathrm{~m}^{2}$ & $25.08 \mathrm{~m}^{2}$ \\
Aspect ratio & 9.79 & 10.0 \\
Tail span & $6.61 \mathrm{~m}$ & $6.60 \mathrm{~m}$ \\
Tail tip chord & $0.653 \mathrm{~m}$ & $0.686 \mathrm{~m}$ \\
Fin tip chord & $0.844 \mathrm{~m}$ & $0.889 \mathrm{~m}$ \\
\hline
\end{tabular}

Table 2. Lift curve slope and drag polar from various techniques

\begin{tabular}{lll}
\hline & Lift Curve Slope & Drag Polar \\
\hline Flight test data & $C_{L}=0.1031 \alpha+0.3393$ & $C_{D}=0.0587 C_{L}^{2}+0.0374$ \\
Wind tunnel results & $C_{L}=0.0939 \alpha+0.1601$ & $C_{D}=0.0543 C_{L}^{2}+0.0287$ \\
Theoretical estimates 16 & $C_{L}=0.0980 \alpha+0.2622$ & $C_{D}=0.0927 C_{L}^{2}+0.0305$ \\
\hline
\end{tabular}

Table 3. Extracted section locations on CAD model

\begin{tabular}{lll}
\hline Section number & $\begin{array}{l}\text { Dimensionless } \\
\text { location }\end{array}$ & $\begin{array}{l}\text { Dimensional } \\
\text { location }\end{array}$ \\
\hline Section 1 & \pm 0.18 & $\pm 1.695 \mathrm{~m}$ \\
Section 2 & \pm 0.29 & $\pm 2.730 \mathrm{~m}$ \\
Section 3 & \pm 0.38 & $\pm 3.578 \mathrm{~m}$ \\
Section 4 & \pm 0.64 & $\pm 6.025 \mathrm{~m}$ \\
Section 5 & \pm 0.80 & $\pm 7.532 \mathrm{~m}$ \\
Section 6 & \pm 0.99 & $\pm 9.321 \mathrm{~m}$ \\
\hline
\end{tabular}

Furthermore, the different turbulence modeling techniques are compared on the basis of pressure coefficient distributions at the different sections mentioned in Table 3 and represented in Figure 1. The root-mean-square (RMS) fluctuating velocity profiles of different techniques are also compared at different lines represented in Figure 1. Line 1 provides the velocity fluctuations in the wake of the propeller, Line 2 gives the velocity profile over the wing surface, Line 3 provides the velocity fluctuations in the wing-tip vortex region, and Line 4 provides the results on the horizontal stabilizer.

2.3. Mesh. In this work, the mesh used by Lawson et al. 7] and Casadei et al. 10 is used for the numerical investigations. The adopted mesh is an unstructured hybrid mesh that is generated by ICEM-CFD software. The outer domain consists of a cylinder with upstream and downstream surfaces placed at ten fuselage lengths and a radius of 5 fuselage lengths. These dimensions ensure that the boundary conditions so not interfere with the flow in the aircraft proximity as well as to be able to capture 


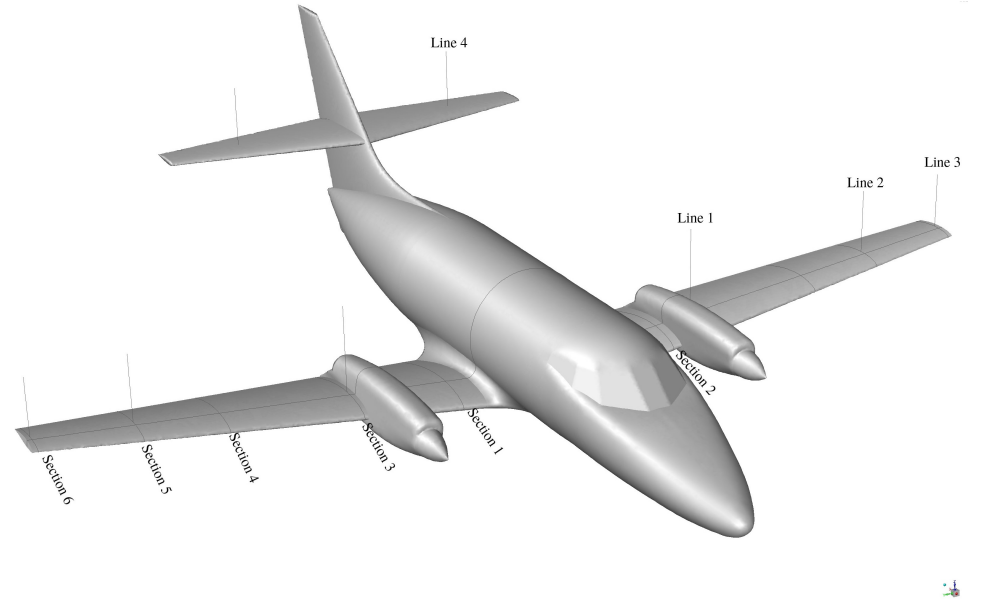

Figure 1. Location of each extracted surface on the Jetstream 31 aircraft

the wake. The front view and side view of the mesh is shown in Figures 2 and 3 respectively. The mesh has a $\mathrm{y}+$ value of approximately 40 as a maximum limit and when extruding the prism layer, the growth ratio and number of layers have been chosen in order to have a total layer thickness equal to approximately $20 \%$ of the boundary layer thickness $7,[10$. The grid convergence study of this mesh has already been performed by Lawson et al. [7], and Casadei et al. [10].

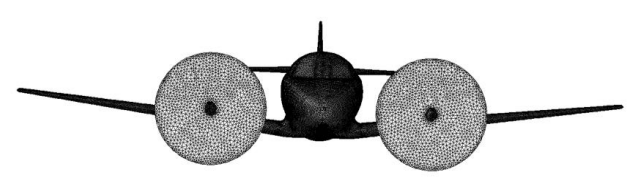

Figure 2. Mesh front view

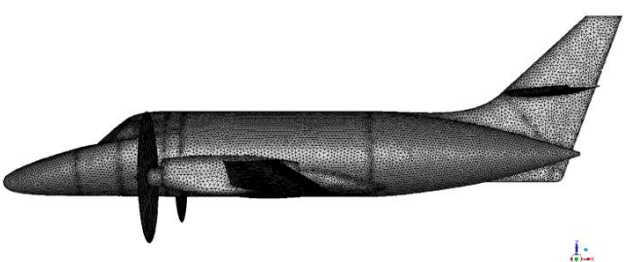

i.

Figure 3. Mesh side view

2.4. Solver settings. The transient simulations are performed using an implicit formulation of a density based solver with the Roe-Flux Difference Splitting (Roe-FDS) Riemann solver. The spatial discretization is performed using the second-order Upwind scheme, and the gradients are calculated using the Green-Gauss node-based method. The time step size of $0.01 \mathrm{~s}$ is used, and a factor of 0.25 is used for the higher-order term relaxation of the flow variables. The pseudo-transient and the wrapped face gradient corrections are not used for the simulations. Note that the discretization of the governing equations uses a first-order scheme and additional terms to employ higher than first-order approximations in the ANSYS-FLUENT environment. Therefore, the use of higher-order term relaxation is recommended for 
transient flow simulations to accelerate convergence of the numerical solution 17 . Finally, the discretization of the turbulent kinetic energy and the specific dissipation rate is done using the QUICK scheme (Quadratic Upstream Interpolation for Convective Kinematics). The propellers are modeled through the use of User-Defined Functions (UDFs) in C programming language using the General Momentum Theory (GMT) 7, 10].

2.5. Boundary conditions. The boundaries of the computational domain are defined with the Robin boundary conditions with pressure farfield conditions. In this study, the air enters the inlet with the density of $0.99356 \mathrm{~kg} / \mathrm{m}^{3}$ at a Mach number of 0.3012 at an angle of $1.9^{\circ}$. This Mach number is near the compressibility limit and results in a velocity of $99.93 \mathrm{~m} / \mathrm{s}$. The angle of attack is modeled by giving the x-component of velocity as $99.87 \mathrm{~m} / \mathrm{s}$ and the z-component of velocity as $3.42 \mathrm{~m} / \mathrm{s}$. The temperature at the inlet is set to be $274.15 \mathrm{~K}$, and the dynamic viscosity is $1.7894 \times 10^{-5} \mathrm{~kg} /(\mathrm{ms})$. These parameters result in the Reynolds number of $9.55 \times 10^{6}$. Where required, the turbulence intensity is set to be $2 \%$, and the turbulent length scale is estimated as about one-fifth of the characteristic length scale, which comes out to be $0.344 \mathrm{~m}$. The wall is defined to be made of aluminum as a stationary wall with a no-slip condition using a smooth wing surface in the ANSYS-FLUENT environment [17. Aluminum has been used, because its properties are the closest to aircraft skin and the wind tunnel test model $[7,10]$.

\section{Results And Discussions}

The simulations are performed on Cranfield University's high-performance computer: CRESCENT, with ANSYS-FLUENT R19.1 using 64 CPU cores along with a GPU, which takes advantage of CUDA-enabled GPU using AmgX as its default linear solver. On an average it took up to 48 hours to complete one DES simulation and up to 40 hours for one URANS simulation.

3.1. Coefficients of lift and drag. Using the drag polar and lift curve slope from Table 2 the lift coefficient for the flight test data is 0.5352 , the wind tunnel is 0.3385 , and the theoretical estimate is 0.4484 . Similarly, the drag coefficient for the flight test data is 0.0542 , the wind tunnel is 0.0349 , and the theoretical estimate is 0.0491 . The lift coefficient obtained from various unsteady simulations is presented in Table 4 and the drag coefficient is presented in Table 5 . The CFD results show significantly large relative differences when compared with the wind tunnel data. This is due to the fact that the model used in wind tunnel simulations did not have the propellers and was scaled to the tenth of the original aircraft. The scaling effect is the cause for high relative differences in $C_{D}$ while not having propellers is the cause for high relative differences in $C_{L}$. These measuring errors are specific to the wind tunnel used and usually depend on its geometrical size. The differences between computational and wind tunnel data which are related to the scaling effects are classified in three parts: geometric model fidelity, pseudo-Reynolds effects and the fact that actual flight Reynolds number is generally difficult to achieve accurately. A detailed discussion of these effects are provided by Pettersson et al. 18 . 
Table 4. Relative differences in lift coefficient

\begin{tabular}{lllll}
\hline Model & $\mathbf{C}_{L}$ & $\Delta \mathbf{C}_{L}$ w.r.t & $\Delta \mathbf{C}_{L}$ w.r.t & $\Delta \mathbf{C}_{L}$ w.r.t \\
& $\mathbf{C F D}$ & Flight test data & Wind tunnel & Theoretical \\
\hline URANS $k-\epsilon$ & 0.4338 & $-18.94 \%$ & $+28.15 \%$ & $-3.25 \%$ \\
URANS RNG $k-\epsilon$ & 0.4142 & $-22.61 \%$ & $+22.36 \%$ & $-7.63 \%$ \\
URANS Realizable $k-\epsilon$ & 0.4282 & $-19.98 \%$ & $+26.49 \%$ & $-4.51 \%$ \\
URANS SST $k-\omega$ & 0.4256 & $-20.47 \%$ & $+25.73 \%$ & $-5.08 \%$ \\
DDES Spalart-Allmaras & 0.4433 & $-17.17 \%$ & $+30.96 \%$ & $-1.14 \%$ \\
DDES $k-\epsilon$ & 0.4141 & $-22.62 \%$ & $+22.33 \%$ & $-7.69 \%$ \\
DES $k-\epsilon$ & 0.4088 & $-23.62 \%$ & $+20.76 \%$ & $-8.83 \%$ \\
\hline
\end{tabular}

Table 5. Relative differences in drag coefficient

\begin{tabular}{lllll}
\hline Model & $\mathbf{C}_{D}$ & $\Delta \mathbf{C}_{D}$ w.r.t & $\Delta \mathbf{C}_{D}$ w.r.t & $\Delta \mathbf{C}_{D}$ w.r.t \\
& CFD & Flight test data & Wind tunnel & Theoretical \\
\hline URANS $k-\epsilon$ & 0.0532 & $-1.84 \%$ & $+52.44 \%$ & $+8.35 \%$ \\
URANS RNG $k-\epsilon$ & 0.0415 & $-23.46 \%$ & $+18.91 \%$ & $-15.47 \%$ \\
URANS Realizable $k-\epsilon$ & 0.0475 & $-12.36 \%$ & $+36.11 \%$ & $-3.25 \%$ \\
URANS SST $k-\omega$ & 0.0418 & $-22.87 \%$ & $+19.77 \%$ & $-14.86 \%$ \\
DDES Spalart-Allmaras & 0.0445 & $-17.89 \%$ & $+27.51 \%$ & $-9.37 \%$ \\
DDES $k-\epsilon$ & 0.0411 & $-24.17 \%$ & $+17.76 \%$ & $-16.29 \%$ \\
DES $k-\epsilon$ & 0.0409 & $-24.54 \%$ & $+17.19 \%$ & $-16.70 \%$ \\
\hline
\end{tabular}

The CFD results still show significant differences compared to flight test data, although now much less than the wind tunnel data. These relative differences can be attributed to the geometrical difference between the CAD model and the original aircraft. Moreover, in CFD analysis, the intake, cooling system and the exhaust of the propulsion system are not modelled. In the CFD analysis, the surface is a clean surface without any rivets or joints, which is not the case in the actual flight. Due to these factors, there are differences in the $C_{L}$ and $C_{D}$ values of CFD and flight test data. The relative differences in CFD results are minor when compared with the theoretical estimates of Cooke [16], with URANS Realizable $k-\epsilon$ model and DDES Spalart-Allmaras model showing the best predictions of $C_{L}$ and $C_{D}$. The better performance of these models was expected for these coefficients, as these models are good in predicting flow conditions far from the boundary layer and thus had better lift and drag predictions. The results of DDES $k-\epsilon$ and DES $k-\epsilon$ could be improved with grid refinement in the region far from the boundary layer. In terms of mesh refinement in the region far from the boundary layer in the DES and DDES simulations, LES mode is activated in the region far from the boundary layer, where results can be improved by refining the grid spacing. Note that the grid refinement can improve the results in the RANS/LES transition region in general. In the cases of DDES $k-\epsilon$ and DES $k-\epsilon$ modelling approaches, the grid refinement may improve the performance of these models in the region far from the wall, because their model constants are tuned for capturing fluid flow physics in the near wall region. On the other hand, 
the DDES Spalart-Allmaras model is an engineering turbulence model, which was specifically developed for aerospace applications. Its model constants are calibrated with the Spalart-Shur correction to achieve the best performance in the region far from the boundary layer. This can be the reason why the grid refinement is not necessary when the DDES Spalart-Allmaras turbulence modelling approach is used in the region far from the wall.

3.2. Flow analysis. Figure 4 represents the pathlines colored with Mach number contours for the simulation carried using the DDES Spalart-Allmaras model. Furthermore, Figure 5 represents the Q-criterion of the simulation at the final time step, which is very helpful in identifying regions of high vorticity. The numerical simulation is able to clearly capture the wing-tip vortices and the vortices created in the wake of the propeller. It is also evident that a nearly elliptical lift distribution exists over the wing. Moreover, at the current angle of attack, the flow over horizontal and vertical stabilizers is unhindered by the wake of the wing, thereby highlighting that complete aerodynamic control can be achieved by the elevator and rudder.
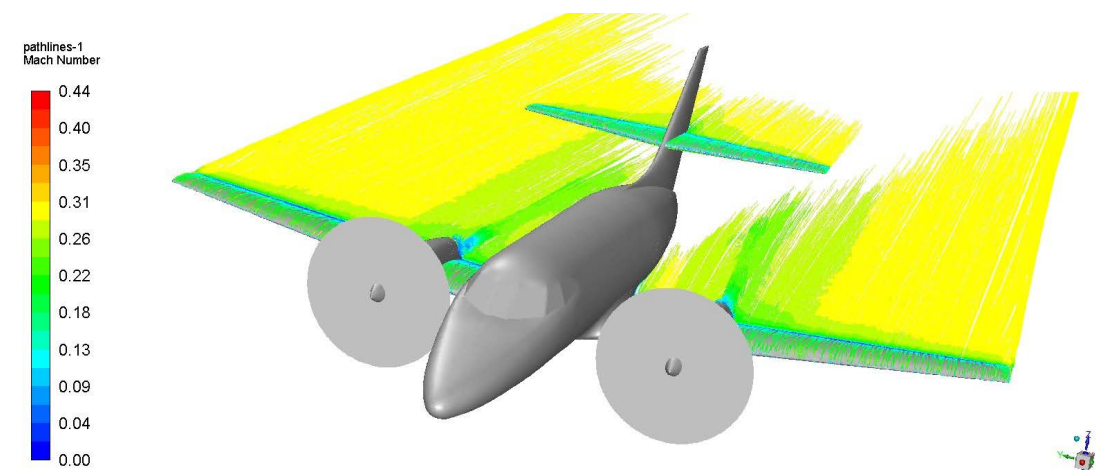

Figure 4. Pathlines coloured with Mach numbers for DDES SpalartAllmaras model

3.3. Pressure coefficient distribution. Figures 6 to 11 represents the pressure coefficient distributions obtained from different turbulence models for the different sections. It is evident from the plots that the peak in $-C_{P}$ values decreases from wing-root to wing-tip. The difference in pressure between the lower and upper surfaces decreases from wing-root to wing-tip as well. These observations highlight that the lift distribution on the wing is nearly elliptical. All the turbulence models show similar values of the pressure coefficient with an exception near the trailing edge of the wing in Sections 3 to 5. It is important to note that an appropriate selection of the turbulence model and the mesh density plays a key role together, especially for hybrid turbulence modeling, because there are no general recipes about how to select them. A possible way is to make a reasonable assessment on both of them and perform grid refinement and parametric studies for the investigated physical problem. Casadei et al. [10] performed a systematic grid convergence study for the Jetstream 


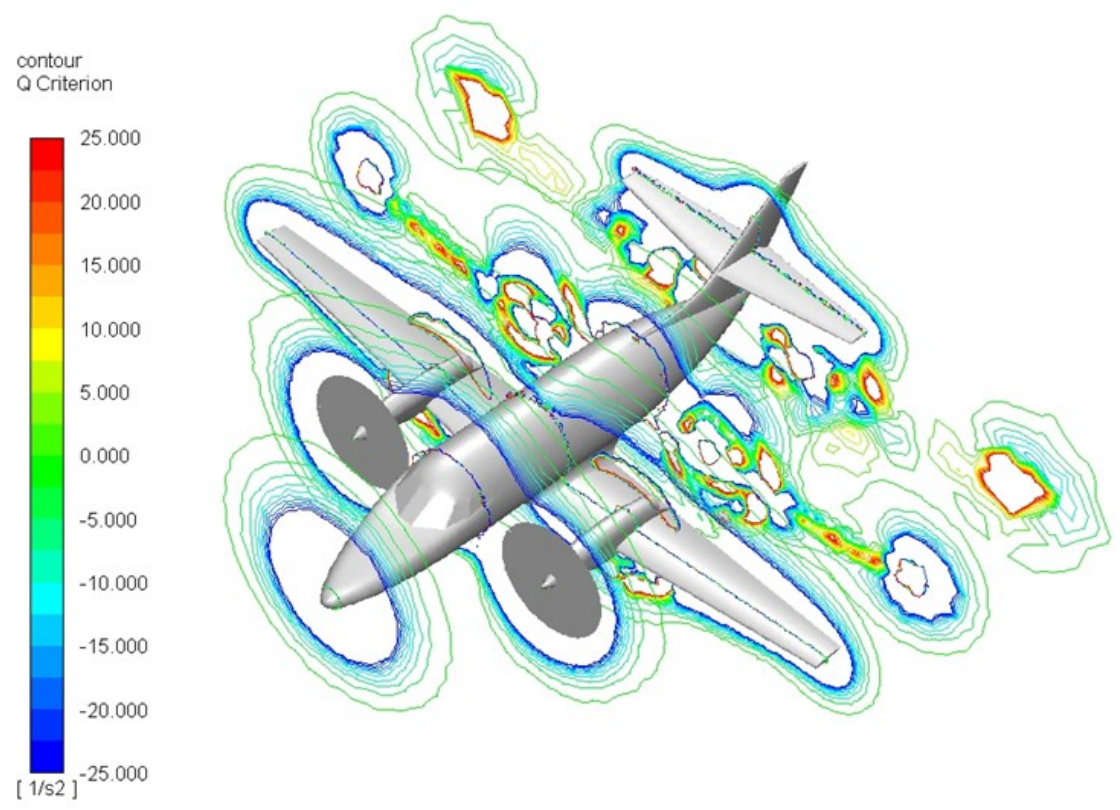

Figure 5. Q-criterion results for DDES Spalart-Allmaras model

31 aircraft which is used in this work and we performed additional simulations.

Since the URANS Realizable $k-\epsilon$ model and DDES Spalart-Allmaras gave the best $C_{L}$ and $C_{D}$ predictions, these will be used as a baseline for calculating the $L 2$ norm of the difference. The L2 norm of the difference between URANS Realizable $k-\epsilon$ and DDES Spalart-Allmaras at Section 1 is $3.23 \%$ and at Section 6 is $1.82 \%$. The L2 norm of the difference between URANS Realizable $k-\epsilon$ and DES $k-\epsilon$ at Section 1 is $3.37 \%$ and at Section 6 is $3.52 \%$. The L2 norm of the difference between URANS Realizable $k-\epsilon$ and DDES $k-\epsilon$ at Section 1 is $2.75 \%$ and at Section 6 is $3.31 \%$. Similarly, the L2 norm of the difference between DDES Spalart-Allmaras and URANS Realizable $k-\epsilon$ at Section 1 is $1.91 \%$. Evidently, there is not much difference between the $C_{P}$ distributions of different turbulence models in Section 1 and Section 6. However, the differences are more apparent near the trailing edge of the wing in Section 2 to Section 5. As Section 2 and Section 3 lie in the wake of the propeller, some oscillations in the $C_{P}$ values are clearly visible.

3.4. Root-Mean-Square (RMS) velocity distribution. The method of computing the Reynolds stress tensor for calculating the turbulent (eddy) viscosity is different for the different turbulence models, thus yielding different velocity fluctuations. Since the time average of these fluctuations is zero, an effective way to examine these is by 


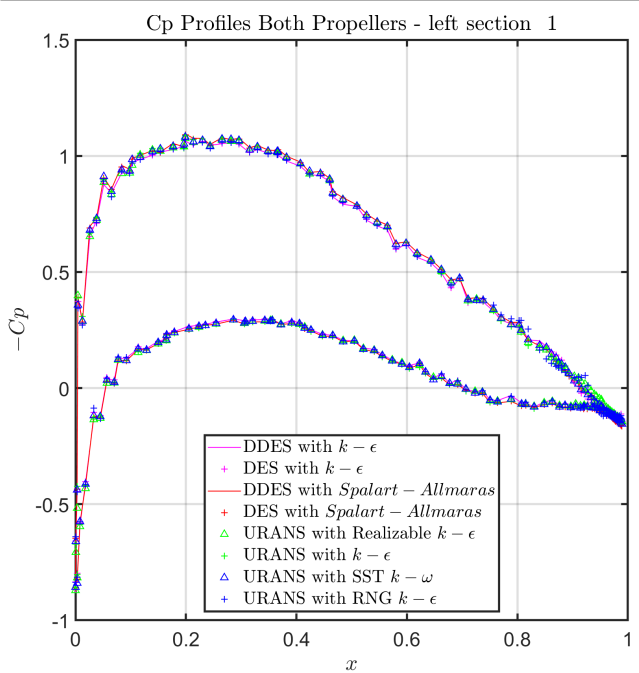

Figure 6. Comparison of pressure coefficients for Section 1

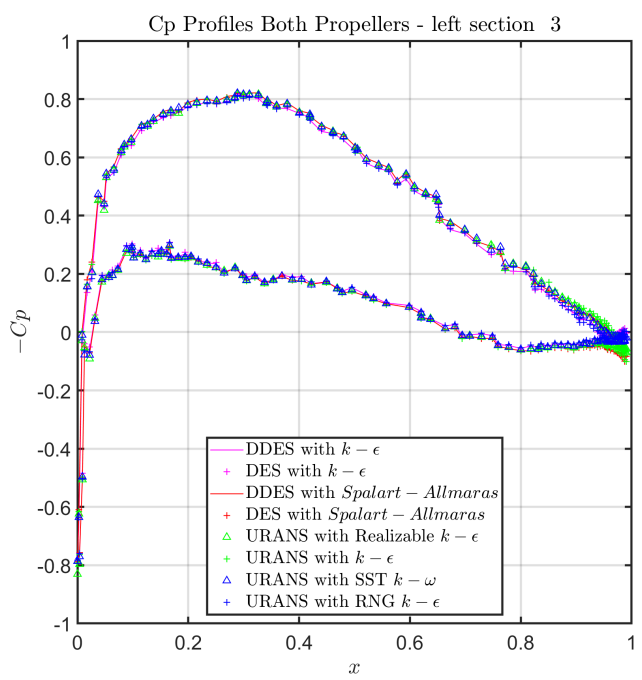

Figure 8. Comparison of pressure coefficients for Section 3

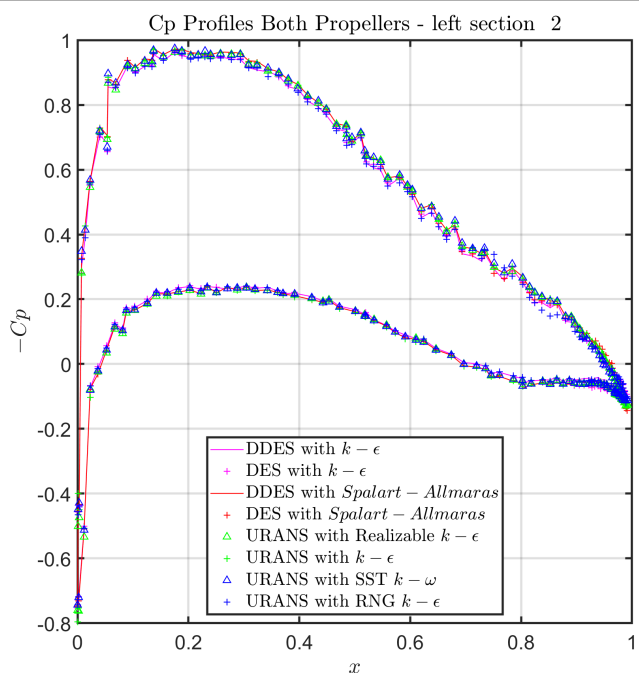

Figure 7. Comparison of pressure coefficients for Section 2

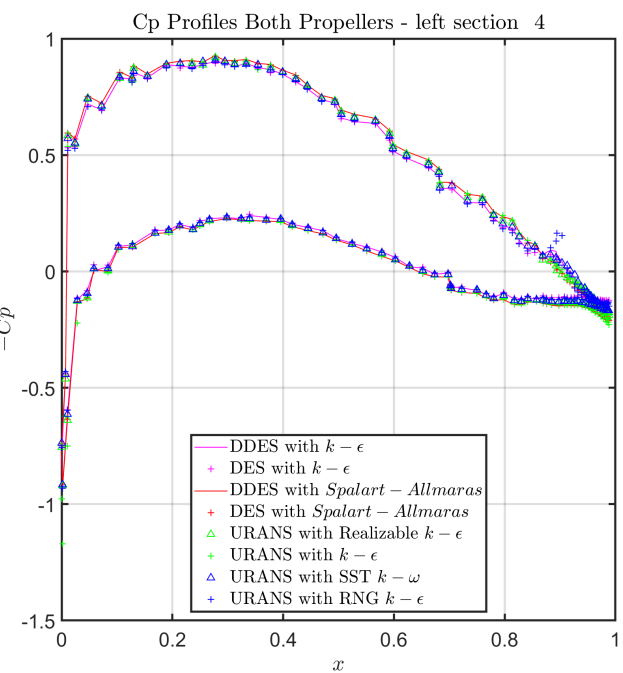

Figure 9. Comparison of pressure coefficients for Section 4

calculating the RMS of fluctuating velocities for the different turbulence models. 


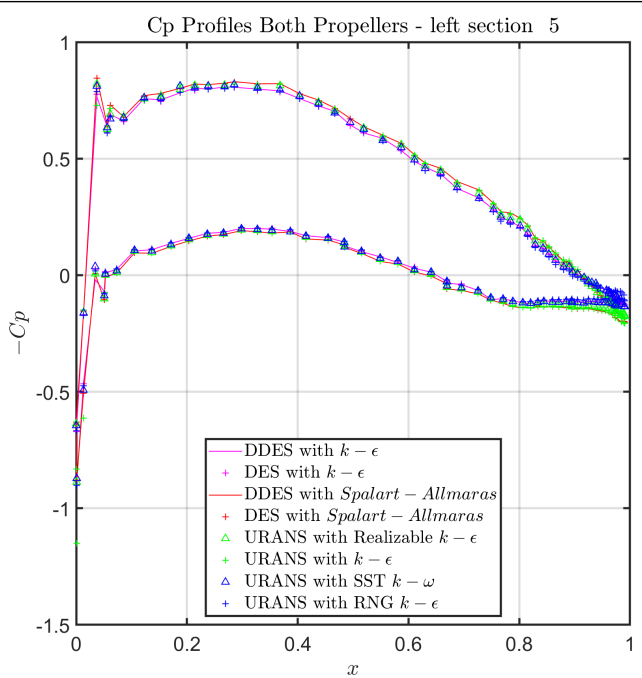

Figure 10. Comparison of pressure coefficients for Section 5

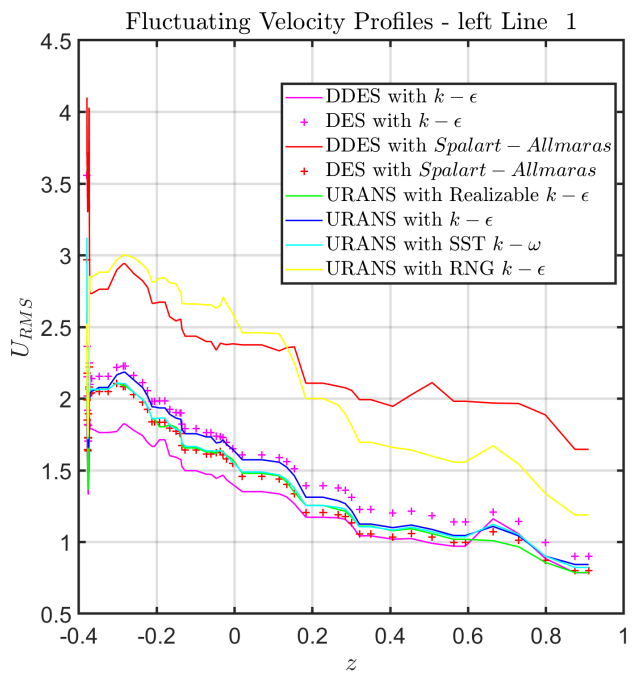

Figure 12. Comparison of RMS fluctuating velocity profile at Line 1

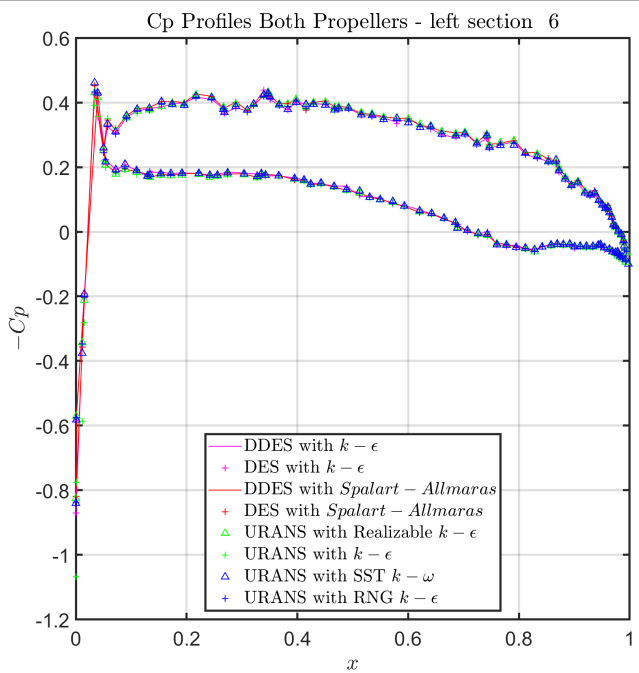

Figure 11. Comparison of pressure coefficients for Section 6

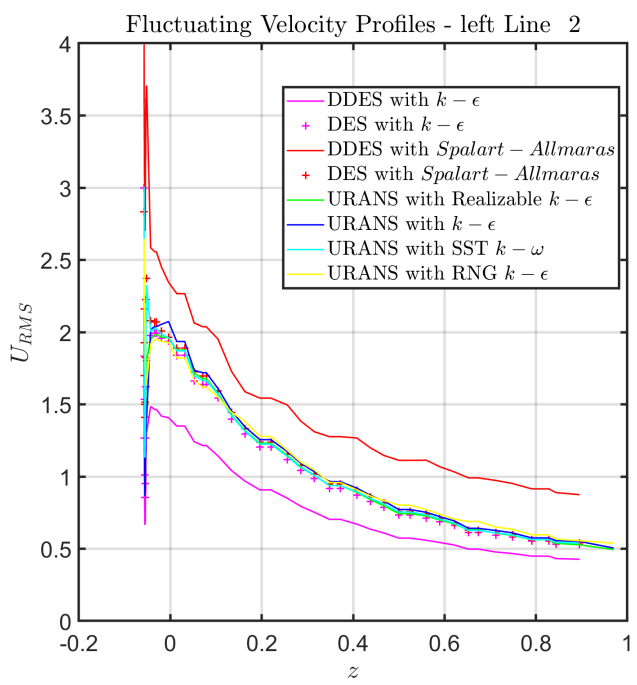

Figure 13. Comparison of RMS fluctuating velocity profile at Line 2

Figure 12 compares the fluctuating velocity profiles in the wake of the propeller (Line 1). As expected, each model captures the fluctuations differently. The URANS RNG $k-\epsilon$ model has the capability to capture rapidly strained flows and outperforms 


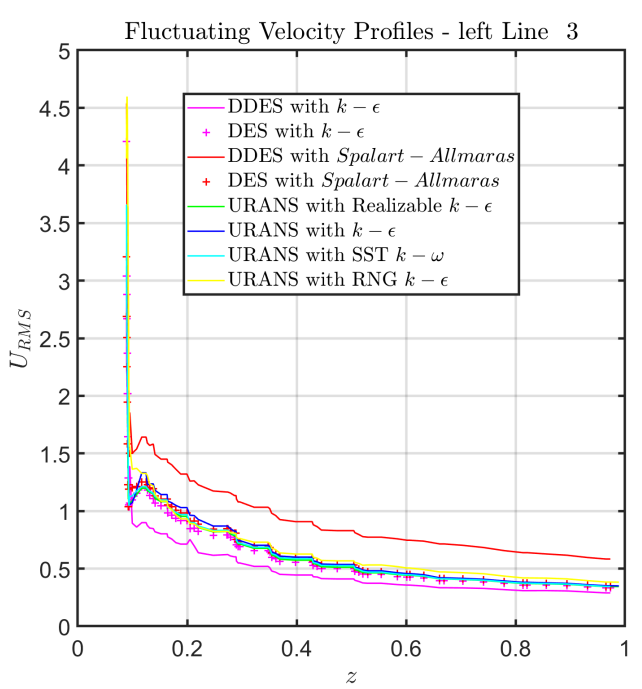

Figure 14. Comparison of RMS fluctuating velocity profile at Line 3

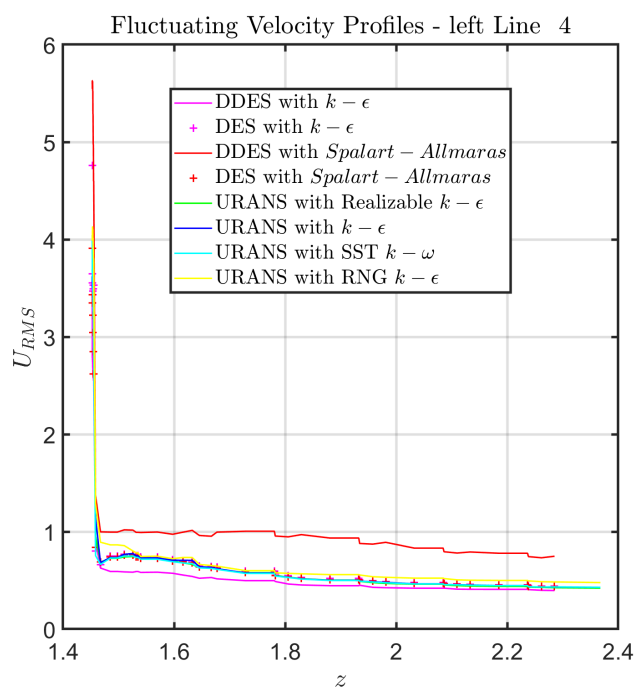

Figure 15. Comparison of RMS fluctuating velocity profile at Line 4

other models in the region as this region is greatly influenced by vortex formation. The DDES Spallart Allmaras model also captures high fluctuations, while the other models also fairly capture fluctuations with a similar pattern. The $L 1$ norm of the difference of the fluctuations between DDES Spallart Allmaras model and URANS RNG $k-\epsilon$ model is $14.06 \%$. Figure 13 compares the fluctuating velocity profiles in the centre of the wing (Line 2). Due to the almost uniform flow, the DDES Spallart Allmaras model and URANS $k-\epsilon$ model are able to capture higher fluctuations than other models. Figure 14 compares the fluctuating velocity profiles at wing-tips (Line 3). Again, the DDES Spallart Allmaras model is able to capture higher fluctuations, while the URANS Realizable $k-\epsilon$ model gives the smaller value of the fluctuations. Figure 15 compares the fluctuating velocity profiles at the horizontal stabilizer of the Jetstream 31 aircraft (Line 4). The flow in this region is partially affected by the wake of the propeller and is unaffected by the wake of the wing. As a result, all the models capture the fluctuations in the same range.

\section{Conclusions}

This paper presented transient simulations of a full-scale Jetstream 31 aircraft using URANS, DES and DDES turbulence modeling approaches. It was found that the lift and drag coefficients obtained from CFD are much closer to the theoretical estimates of Cooke 16 than the results of the flight test or wind tunnel data. The difference between CFD and wind tunnel results is attributed to the scaling effects and absence of a propeller in the wind tunnel model. On the other hand, the difference between CFD results and flight test data are attributed to the minor geometrical difference between 
the CAD model and original aircraft, and the absence of modeling of various elements of the propulsion system. Therefore, in order to reduce the error between CFD results and flight test data, the simulation setup should include effects like surface roughness, intake and exhaust of propulsion system and so on. The inclusion of these models will increase computational time, but this will be offset by advancements in computing. These results highlight that although there are some differences between CFD results and flight test data, the detailed flow characteristics obtained from CFD certainly help in optimizing the design and reducing the overall development cost of any new design project.

For the mesh and the conditions presented in this study, the DDES SpalartAllmaras model gives the best overall results with the highest accuracy of lift coefficient, the relatively good performance in the drag coefficient, and consistently capturing the fluctuations in the velocity. The results from the DDES $k-\epsilon$ model and DES $k-\epsilon$ model were not that satisfactory. However, the results from these models will surely be improved by refining the mesh in the region far from the boundary layer. Finally, all turbulence approaches used in this study provided almost the same pressure coefficient distribution with a slight exception near the trailing edge of the wing.

Acknowledgements. This research work was financially supported by the Centre for Computational Engineering Sciences at Cranfield University under project code EEB6001R. We would like to express a special thanks to Professor Nicholas Lawson, former Head of the National Flying Laboratory Centre (NFLC) at Cranfield University, for providing the flight test data. Furthermore, we would like to acknowledge the IT support for using the High Performance Computing (HPC) facilities at Cranfield University, UK.

\section{REFERENCES}

1. R. Parker. "Investigation and development of a 3D non-contact scanning process for CFD model generation." Ph. D. Dissertation. Cranfield University, 2006.

2. C.W.E. Leung. "CFD Modelling of the fluid flow around a BAE Systems Jetstream 31 Equipment Pod." M. Sc. Dissertation. Cranfield University, 2008.

3. C. Vessot. "CFD Aerodynamic Model of the Jetstream 31." M. Sc. Dissertation. Cranfield University, 2012.

4. J. Hodara. "Computational 3D modelling of propeller effects on the boundary layer of a Dornier Fo-228." M. Sc. Dissertation. Cranfield University, 2012.

5. M.L. Pajolec. "Investigation of propeller theories on BAE Jetstream 31 CFD model." M. Sc. Dissertation. Cranfield University, 2013.

6. H. Jacques. "Simulation of propeller effects on the Jetstream 31 Aircraft." M. Sc. Dissertation. Cranfield University, 2014.

7. N.J. Lawson, H. Jacques, J.E. Gautrey, A.K. Cooke, J.C. Holt, and K.P. Garry. "Jetstream 31 national flying laboratory: Lift and drag measurement and modelling." Aerospace Science and Technology, 60, (2017), pp. 84-95. DOI: 10.1016/ j.ast.2016.11.001.

8. K.A.A. Fayyad. "CFD Analysis of propeller effects on Jetstream 31." M. Sc. Dissertation. Cranfield University, 2016. 
9. Y. Zhu. "Simulation of feathered propeller on the Jetstream 31 Aircraft." M. Sc. Dissertation. Cranfield University, 2016.

10. L. Casadei, L. Könözsy, and N. J. Lawson. "Unsteady Detached-Eddy Simulation (DES) of the Jetstream 31 aircraft in One Engine Inoperative (OEI) condition with propeller modelling." Aerospace Science and Technology, 91, (2019), pp. 287-300. DOI: $10.1016 / \mathrm{j}$. ast.2019.05.034.

11. B. E. Launder and D. B. Spalding. "The numerical computation of turbulent flows." Journal of Scientific Computing, 3, (1974), pp. 269-289. DOI: 10.1016/ 0045-7825(74)90029-2

12. T.H. Shih, W.W. Liou, A. Shabbir, Z. Yang, and J. Zhu. "Two-equation eddyviscosity turbulence models for engineering applications." Computer and Fluids 24(3), (1995), pp. 227-238. DOI: 10.1016/0045-7930(94)00032-T.

13. V. Yakhot and S.A. Orszag. "Renormalization group analysis of turbulence." Journal of Scientific Computing 1(1), (1986), pp. 1-51. DOI: 10.1007/BF01061452.

14. F. R. Menter. "Two-equation eddy-viscosity turbulence models for engineering applications." AIAA Journal, 32(8), (1994), pp. 1598-1605. DOI: 10.2514/3. 12149 .

15. M.L. Shur, M.K. Strelets, A.K. Travin, and P.R. Spalart. "Turbulence Modeling in Rotating and Curved Channels: Assessing the Spalart-Shur Correction." AIAA Journal 38(5), (2000), pp. 784-792. DOI: 10.2514/2.1058.

16. A. K. Cooke. "Simulation model of the NFLC Jetstream 31." Report. Cranfield University, 2006.

17. Ansys. "Fluent 19.1 user's guide." Help system. ANSYS, Inc., 2019.

18. K. Pettersson and A. Rizzi. "Aerodynamic scaling to free flight conditions: Past and present." Progress in Aerospace Sciences, 44(4), (2008), pp. 295-313. DOI: 10.1016/j.paerosci.2008.03.002. 